\title{
Introduction to the Special Issue: Media and Ethnic Minorities in Europe
}

LEEN D'HAENENS and CHRISTINE OGAN

Across the countries of Europe and within the European Union, there seems to be no end to discussions of policies related to migrants - from the labor migrants who came to Europe more than 40 years ago to the continued requests from prospective migrants who want to immigrate for asylum and family formation. The discussions on what those policies should be, range from multiculturalism to integration and assimilation. Shifts in policies have occurred because of the slow economic and educational progress made by some migrants; by the post-9/11 changes in attitudes and behavior among some Muslim migrants, and by concerns over the increased size of the migrant population.

One of the key concepts throughout this special issue is 'integration'. Integration can be interpreted in many ways, but it is unthinkable without the following two components: the acknowledgement of diversity, and the pursuit of equality. The different geographic regions under study in this issue, with distinct social and political climates, are adopting diversity policies which, by and large, and allowing for similarities as well as dissimilarities, have the same expectations of 'newcomers': coping abilities, personal responsibility and active citizenship. Outlining a connective policy as an answer to a number of intractable problems is a real challenge. Ethnic minority groups and the native population, although living side by side, take little notice of each other; inter-ethnic contacts continue to be scarce, the image that the groups create of each other tends to become less flattering, and finally, the social-economic disadvantage of the migrant population continues to be highly problematic. Moreover, frustration at this discouraging situation turns out to be greatest among the highest-skilled migrants. Research has shown, nevertheless, that skilled immigrants do adjust more easily, but that economic integration does not ensure cultural and social integration.

One sign that such integration is not progressing in the way governments would like can be seen in the incidence of clashes between individ- 
uals representing majority and minority populations. Violence based on religious differences in Europe has been on the rise. In Denmark, the publication of the anti-Muslim cartoons, and in the Netherlands the assassination of Pim Fortuyn, a conservative politician, and the assassination of filmmaker and critic of Islam, Theo van Gogh, have served as triggers for the increases in xenophobic and racist acts committed in 2006 as documented by the European Monitoring Center on Racism and Xenophobia (EUMC). Franco Frattini, European Commission VicePresident responsible for Justice, Freedom and Security, said that 2006 marked a record year for neo-Nazi crimes in Germany and that the surge in racist acts in many European countries had increased by 25 to 45 percent over the previous year. The EUMC has cited inadequacy of official criminal justice data on racist violence, discriminatory practices in labor, housing and education, and failure to fully implement the EU anti-discrimination directives as reasons for the continuing problems for ethnic minorities.

What role do the media play in thematizing and resolving these problems? In order to improve the image of the 'majority' as well as of the 'minority' in each other's eyes, portrayal is undoubtedly influential in the shaping of people's opinions about ethnic minorities. This is the case if only because most people do not have direct contact and exchange with ethnic minorities and thus rely on hear-say and the media as main sources for their knowledge about ethnic minority groups and issues. Numerous content analyses have identified recurrent negative portrayals characterized by generalizations and explicit associations of ethnicity with predominantly negative news contexts. Portrayal, however, is not the angle of study chosen in this special issue. What it does include is research on media use and media menus of ethnic minorities, as mass media have been seen as the way to help immigrants adjust to their new lives in Europe. But mass media - particularly television, newspapers, and the Internet - also offer comfort to those who find themselves missing their home countries. Satellites and broadband Internet access have brought distant information and entertainment into the European homes of the migrants. Information and communication technologies constitute yet another focus for addressing a range of migration issues. Policymakers and researchers have viewed the global and local media environments from several perspectives. Some have expressed concern that the media from the home countries of the migrants prevent them from fully integrating into their new countries of residence. Others find that many migrants can move easily between host country media to home country media.

The Internet has offered opportunities for people to set up forums and chat rooms to discuss issues pertaining to ethnic minorities. This has 
been an especially important communication medium for young people wondering about their identities. Both the mass media and the Internet have obligations to be inclusive in their portrayal of the lives of ethnic minorities, in the openness to participation by all groups in interactive media, and in the employment of less represented groups in society.

This issue provides a range of research that examines media use, media images, and integration in Belgium, Germany, the Netherlands, and Switzerland. Taken together, the studies provide a more nuanced picture of ethnic minorities' interaction with society through the mass media and the Internet. Youth are a particularly important group to examine as they are major media consumers and their interests need to be taken seriously. In the Bonfadelli, Bucher and Piga article, the authors comparatively analyze the use of mass media and the Internet, and the relation to social integration and cultural identity by Swiss adolescents. They also make comparisons between the Swiss youth and other research conducted with European youth from other countries. Trebbe examines use of Turkish and German media by young people in Germany, who mostly represent the second or third generation of migrants. Focusing on the people living in the North Rhine Westphalia district, the author examines the influence of mass media on the acculturation of youth, and asks whether consuming larger amounts of media from Turkey has a negative impact on their level of integration into German society.

If young people form their identities, at least partially, on the images of themselves that they find in the mass media, then it would be important for advertisers to represent ethnic minorities in a positive light, emphasizing the ways these groups can be positively represented in the multicultural environment. Koeman takes a first step in studying this issue by examining the values and communication styles used by advertisers from several countries, focusing on advertising comparisons in countries that have been classified as individualistic vs. those which are said to be collectivistic.

Gezduci and d'Haenens focus on the media exposure and use of adults in their study of 400 ethnic Turks in Belgium (Flanders and Brussels). As satellite television programs from Turkey are widely received in the country, the authors focus on the role played by both Belgian and Turkish media in the lives of the respondents. They find that the strongest determinants for media use in Turkish are religion, ethnic and cultural position, and command of the Turkish language, while use of Belgian media is determined by command of Dutch or French, how long they had lived in Belgium, and their educational level. Van Summeren also found that religion was an important factor for Moroccan minority youth in the Netherlands who make regular use of a web site (Moroc.nl). She examined six dimensions of religious experience (i.e., the ritual, 
ideological, consequential, experiential, intellectual, and social) in more than a thousand online messages sent on the web site.

Research conducted among ethnic minorities in European countries can be difficult due to its sensitive nature, and in the current time when tensions between majority and minority populations are so high. In her study of the use of mass media and the Internet by newer Turkish migrants in the Netherlands, Ogan encountered a variety of barriers, causing the outcome of the study to fall short of the goal. She describes the range of methodological and ethical issues confronted in her months of data gathering.

The individual articles in this issue focus on specific populations or specific media content, but together they provide new in-depth information on mass media and new media use, and should inspire other research that brings greater understanding rather than more anti-immigrant feeling across the different countries treated in these articles. 